\title{
Women's Opportunity of Education in Rural China
}

\author{
Yuying Wang* \\ College of Arts and Sciences, University of Washington, Seattle, Washington 98195, U.S.A. \\ *Corresponding author. Email: yuying25@uw.edu
}

\begin{abstract}
Being equal in education is always a significant problem for China. Since the establishment of the new China, the Chinese government has published many policies to balance the different education situations between people, like the expansion of higher education and the compulsory education system. The country provides more educational opportunities for residents. According to recent reports, almost all the people in the school-age are able to go to primary school, and the ratios of males and females' enrollment in higher education are also nearly equal. However, the data describing the education situation for every province in China shows that there is still education inequality between cities and countries. Also, the gender gap in education in rural areas is significant. Women in countries have fewer opportunities to go to school than other people in China. This article reviews the early research about education inequality and discusses two popular theories in past studies. Then, it focuses on how a person's family factors influence gender inequality in education in rural China. The early studies show that a person's academic performance is not why women have fewer studying opportunities than men. Parents' educational levels, the number of siblings, and the family economic situation affect a person's education attainments and influence the girls more than boys. In rural China, the statistics show that the average educational levels of parents are lower, a family has more children, and the economic situation is worse than in the city. They may be the reasons for the gender gap in education in rural China. For future research, it will be meaningful to find the children's thoughts of going to schools. Knowing why people want or don't want to study and what influences their thoughts will be helpful to improve the educational system in China.
\end{abstract}

Keywords: gender, education, rural region, family, patriarchy

\section{INTRODUCTION}

The two significant goals of gender equality in education are the gender parity goal and gender equality goal. For gender parity, it means reaching equal proportions of boys and girls in the same age populations participating in all types of education. The gender equality goal aims that education that boys and girls receive is equally qualitative [1].

As early as during the New Democratic Revolution in China, the founder of China called Mao Zedong attached great importance to women's emancipation, saying that the day women rise throughout the country is the day the Chinese revolution will be won. Education is recognized as a significant factor for reaching gender justice [1]. Gender equality in education is always an important goal for China. As the development of economy, the Chinese government published a series of policies like the higher education expansion, a compulsory education system. Beginning with 1949, gender inequality in education has been undisputedly decreasing. From the 1980 s to the 2000 s, the gender inequality against girls decreases from $81 \%$ to $54 \%$ [2]. China restored the college entrance examination in 1978 and expanded the higher education enrollment significantly in 1999. The percentage of women in the universities increased a lot and to nearly 50\%. Some researchers believed that gender inequality in educational opportunities would be disappeared [3]. The report published by the Ministry of Education of the People's Republic of China in 2019 shows that the net enrolment ratio of school-age children in primary school was $99.95 \%$ [4]. It reflects that almost all school-age children can enter primary school in China now.

According to the 2019 China Statical Yearbook, it shows that among the population over 15 years of age in China, the proportion of illiterate women is 3.158 times higher than that of men [5]. The number of women who do not attend primary school is 2.527 times more than men [5]. These reports also show the location 
distribution data, and many illiterate women are from the rural and northwest regions in China like Gansu, Xinjiang, and Xizang. According to the data from Chinese General Social Survey (CGSS) 2017, for females in the age range between 18 to 49 years old, the education level of $40.59 \%$ of them is at or below elementary schools [6]. According to the data above, a massive group of women in China does not receive education well, especially for the women in rural areas, and the different situation between women and men says that gender inequality is still a problem in China.

Education is one of the most important factors for one's development. It helps people to receive knowledge, meet new people, and build worldview. Education has a significant influence on people's first and current careers [7]. Therefore, many researchers are paying much attention to the factors that influence gender inequality in rural China and try to find the answers to fix them. This article will discuss the early studies, compare the results, and analyze from a new perspective about future learning. The paper will separate into three parts: 1) It will review the previous researchers' theories that may explain the phenomenon of educational inequality. 2) It will conclude and compare the previous research findings and data that study how people's academic performance, parents' educational levels, the number of siblings and family economic situation influence the gender inequality in education in China. 3) It will discuss the research gap and future research direction.

Almost all the previous studies about Chinese gender inequality in education focused on external factors. There is no specific research on the impact of people's ideas on education equality and the factors that influence one's education choice. It may be a good direction for future study and help to improve gender equality in education.

\section{EDUCATION IN CHINA}

\subsection{Theory}

Education equality is a critical problem globally, and many researchers have done some studies to test the hypotheses about education equality. Most of the research focused on how a people's native factors like parents, social class, and family constructions influence their educational chances. A large part of the researchers who studied educational gender inequality in Chinese built their hypotheses based on industrialization thesis and theory of social reproduction.

\subsubsection{Industrialization}

Industrialization theory predicts that the education inequality will decrease with industrial development. For the industrial society, occupational divisions will become increasingly specialized and refined. Society will need the people to be professional and capable, which will require the people's effort and talents. Education is a way to provide working skills to the people and put them in the matched position in the community. On the other hand, there is more requirement on a person's ability, and the social class level will tend to be equal for every resident. The born with factors like genders, race, and social classes will influence the smaller for receiving education [8] [9]. For these reasons, gender inequality in education will decrease with the development of society in China.

Based on industrial theory, previous researchers made the hypotheses and tested them about education equality. In 1978, Featherman and Hauser found that family background as a factor for primary and secondary education, its influence decreased [10]. However, many later studies rejected this opinion. In 1981, Mare designed the transition model to test how family background influences the educational level and found that the influences from family increases [11]. One early article that studied the chronological trends in Chinese education analyzed the data by combining the policy and education distribution. The researcher assumed that the education inequality should be decreased first and then increased since 1949. Because after the People's Republic of China was established in 1949, the government pursued the policy of egalitarianism in the education field, and the difference between social classes decreased. Beginning with 1978, with the economic reformation, the government transformed equal education into elite education, which caused the more significant gap between social classes. However, according to the collected data, the education inequality in these two periods had no difference [8]. Another study compares the gender gap in the education of the people born in 1950 - 1990 and finds the difference between women and men reduces minimally [12]. These results showed that the industrialization of China doesn't affect equality in education a lot.

\subsubsection{Family Situation}

One theory that holds a different idea with industrialization is called reproduction [13]. This theory emphasizes that education is a way for the social groups with advantages to keep their power and push the lowerclass groups to be more away from them. The upperclass people use their power to keep their children going to the top school, receiving a high degree, and getting a good job. The round will keep rolling, the powerful family will reproduce upper-class people by education, and the low-class people are hard to go up. On the other hand, a family's cultural and economic capital can accumulate and pass to its descendants. It can help the children become successful easier than others. For a child's academic achievement, his social origin 
background may be more important than the school quality [14]. Therefore, people's support from their families is a significant factor in their educational opportunities.

Based on the reproduction theory, many researchers compared the education situation in urban areas and rural areas in China. Even though the Chinese government offered the decentralization policy to the rural areas, the economic and education situations inequality between countries and cities is still huge. Poverty in rural areas has been a big problem for the Chinese government through the 1990s [15].

One previous researcher who studied the educational years of people born in 1950 to 1989 compares the differences between city and country, city women and men, and rural women and men. By drawing a line graph with the year of birth as the independent variable and the dependent variable is the school years, it shows that with the time change, the education levels increase both in countries and cities, but the difference between them has no changes. For the city, gender inequality decreases, and it has been almost no difference between women and men in recent years. However, the gender gap in rural area is still big [12]. The article from the same writer analyzes the data from CGSS 2008. Keeping all other factors being the same, the education years of Chinese females is 0.879 less than Chinese men. By adding the impact of household location, the result shows no significant difference in education length between women and men in urban areas in China. However, the rural women's average year of education was 1.393 years less than rural men [16]. Another study that focused on higher education in Chinese had a similar found. For the rural area in China, higher education opportunities for men are 2.3 times greater than for women, but in other areas of China, males' chances are $11.22 \%$ lower than females' [9].

Early research showed that educational inequality between city and country still exists in China, and gender inequality in rural areas is also a significant problem. Based on these two theories, researchers work on how a person's ability and some aspects of background specifically influence the rural area females' education

\subsection{Academic Performance}

Some early opinions believe the gender inequality is because of academic performance. Many people used to think that boys would study better than girls, so boys should go to school. However, current studies prove that women's school performances are as well as men's and even better than men. One study used general criteria to find the articles related to the educational attainment outcome and collected the data from these studies. About only 14 percent of the studies said that boys perform better than girls, and about half of the studies proved that girls work better in schools [2].

On the other hand, a study is about the era trends of education in China. By analyzing the data about the people who were born in 1940 - 1989, the men have 3.4 times more opportunities than women have to go to primary school and the differences between women and men keep decreasing sharply when from primary school to middle school, and the middle school to high school. There is no significant difference when women and men are from high school to college. It means that once the women have a chance to attend primary and secondary school, their promotion competitiveness is like men [8]. The differences in education chances between urban people and rural people are similar to the females and males. It may prove that the inequality in education for rural women is not because of their capability or academic performance but the chance to receive primary education. The opportunity for women to go to primary school is a significant problem.

\subsection{Parents' Educational Level}

The early research shows that parents with high educational levels, their children will have advantages in studying. The family's cultural background will influence the children in three ways, parental shaping of educational expectations, the family's cultural atmosphere, and studying tutoring [17]. Parents can influence their children's opinions, and when parents have high and reasonable expectations of their children, they may improve children's aspiration to study. Higheducated parents may provide children with a better studying environment, and when the children have problems during studying, parents can teach them.

The education level of parents is a standard variable for many previous studies about Chinese education equality. One early research finds that as fathers increase one year of education, their children's opportunities to go to primary school, promote to middle school, high school, and college would increase $17 \%, 13 \%, 11 \%$, and $13 \%$ [8]. Furthermore, many researchers pay attention to how education background influence educational gender inequality. A study shows that when the father is at or below the elementary school, males' chances of higher education will be 2.29 times higher than that of female. When parents have junior high school education and above, the difference between women's chances of high education and men's shows no statistically significant [9]. A study has also shown that parents' educational background does not have the same degree of influence on boys and girls. Keeping all the other variables being the same, as parents have one more education unit, their daughter will have 0.287 more units of education, and their son will have 0.166 units more [16]. Overall, the previous research shows that parents' education level will 
influence children's education experience and affect women and men differently. Gender inequality will be increase when the parents with lower education levels.

By analyzing the data from CGSS 2008, the results show that the average educational years for parents in the country is 4.82 years and in the city is 7.79 [12]. There is a big difference in parents' educational levels between rural areas and urban areas. Also, early research tells that the parents' educational level will influence the women more than boys. It may be a reason why women in rural areas of China have less chance of education.

On the other hand, one study on the influencing factors of gender perspective. In China, there are some traditional concepts that women should stay at home and men should go out for works, a girl does not need to read books, and for women, it is better to marry well than learn well. The participants do a survey, and the higher scores indicate that participants are more patriarchal than those with lower scores. The final results show that the score men have for each additional year of education will reduce by 0.69 , and for women, the scores will reduce by 0.95 [18]. Children's aspiration of studying will be influenced by the surrounding environment and their parents' attitudes, especially for girls [19]. Gender stereotype is a primary reason for the gender inequality in rural areas [20]. Parents in rural areas have fewer average education years and may influence their perspective of gender. These may be the reasons for the gender inequality in rural China.

\subsection{Family Situation}

Two major points that may influence the gender inequality in the country may be the family economic situation and how many siblings he has. Many early studies have proved a positively correlated relationship between a family's economic situation and children's opportunities for education [14, 17]. There is no significant difference in gender inequality between families with the different economic situations of a family. In the study about high education, when the economic level of one family increases one level, the opportunities to receive high education will increase 1.13 times for both females and males [9]. In contrast to this result, one article that focuses on the gender difference between academic years finds that gender inequality in a lower economic status household is more serious than the higher one. The economic situation of a family influences the daughter more than the son [16].

Based on the resource dilution theory, a family's resources to their children are limited [12]. Therefore, the number of siblings will influence one's educational investment from the family, and it may influence females and males differently since many Chinese rural parents will make the educational decision based on the family economic future. They believe that sons are more worthy of education since they can earn higher wages in the future, and many parents in China believe that they need to rely on sons at old age [21]. For these reasons, when there is not only one child, parents may not invest all children in the family equally.

From previous studies, one typical result is education obtaining has no difference between females and males when he or she is the only child in the family. Compared to the child in the multi-child household, the girl who lives in a one-child family improves more than a boy [22]. For each additional sibling, the years of schooling for a boy will decrease 0.084 years, and for girls will decrease 0.414 years [16]. When there are more siblings in a family, the gender inequality in a family will be serious. By describing the data from CGSS 2008, the result shows that the average number of siblings for people in the urban area is 2.305 , and for urban area is 3.21. The higher number of siblings that rural women have may be one factor that influences their educational chances.

\section{CONCLUSION}

Since the People's Republic of China is established in 1949, the Chinese education inequality declined sharply. More and more people have opportunities to go to school because of the compulsory education system. However, the government should focus on the general data for the whole country and pay attention to the specific non-dominant group. According to the current data collected from Chinese residents, educational gender inequality in China still exists. Rural women are the group that endures the most discrimination in education. Because of their physical condition, the differences between the city and the country are still huge now. In rural China, the school numbers, the quality of teachers, and the financial situation are all problems that need to be solved. Some policies may be published for rural regions, like providing more funds to establish more schools and giving welfare to teachers in the country. Family factors that are talked about above are also critical. For the student from a family with economic difficulties, the government may provide a subsidy policy to the students who want to and are able to go to school but cannot afford the tuition fees. In rural areas, many people still hold the traditional gender values. Early research proved that a girl's aspiration of studying is influenced by her mother's gender attitude a lot [19]. It is hard to change one's traditional gender values in a short time. One thing that may improve is that schools can provide gender-related courses to the students and build the ideal of gender equality to the people since they are very young.

Almost all the previous studies focus on the external influencing factors for one's education. There is no specific research on the effects of one's own thoughts. 
For example, most research does not consider whether this child does not continue going to school because of his own choice. Many children may decide not to go to college and work after middle school or high school by themselves. Sometimes, the parents push their children to go to school, but children don't want to study. What is the difference between one's thoughts of not going to school between men and women, city and country and why don't they want to go to school? What influences their thoughts? Girls in rural China who don't want to go to school may be influenced by their parents' perspective of gender values, like women's job is taking care of the family, so they don't need to go to school. Some boys may believe studying is useless, and they can do something else that is more interesting. Children in the family that has economic difficulties may want to work early to support the family. A systematic study on why the children decide not to go to school may be a meaningful direction for future research. It may help improve the likelihood of people's study.

\section{REFERENCES}

[1] Subrahmanian, R. Gender equality in education: Definitions and measurements. International Journal of Educational Development, vol.25, pp.395-407, 2005.

[2] Zhang, J., Pang, X., Zhang, L., et al. Gender Inequality in Education in China: A MetaRegression Analysis. Contemporary Economic Policy, vol.32, pp.474-491, 2014.

[3] Liu, J. Differences in Higher Education Expansion and Enrolment Opportunities: 1978-2003. Chinese Journal of Sociology, no.3, pp.158-79, 2006.

[4] Ministry of Education of the People's Republic of China, [online] Available: http://www.moe.gov.cn/s78/A03/moe_560/2020/qu anguo/202108/t20210831_556355.html.

[5] China Statistical Yearbook 2020, [online] Available: http://www.stats.gov.cn/tjsj/ndsj/2020/indexch.htm

[6] He, X., Lin, L. Household Income, Female Education Level, and Second-child Fertility Intentions of Chinese Women of Childbearing Age. Fujian Tribune, no.3, pp.98-108, 2021.

[7] P. M. Blau and O. D. Duncan, The American Occupation Structure. New York: John Wiley, 1967.

[8] Li, C. The Changing Trend of Educational Inequality in China (1940 - 2010): Re-examining the urban-rural gap on educational opportunity. Sociological Study, no.2, pp.65-89, 2014.
[9] Zhang, Z., Chen, Q. Collee Expansion and Gender Equalization in Higher Education: An empirical study based on 2008 Chinese general social survey. Sociological Study, no.2, pp.173-196, 2013.

[10] D. L. Featherman and R. M. Hauser, Opportunity and Change. New York: Academic Press, 1978.

[11] Mare, R. D. Change and Stability in Educational Stratification. American Sociological Review, vol.46, no.1, pp.72-87, 1981.

[12] Wu, Y., Huang, C. A study of urban-rural differences in gender inequality in Educational Attainment in China. Journal of Chinese Academy of Governance, no.2, pp.41-47, 2015.

[13] Collins, R. Functional and Conflict Theories of Educational Stratification. American Sociological Review, vol.36, no.6, pp.1002-1019, 1971.

[14] J. Liu, The State, Social Class and Education. Beijing: China Renmin University Press, 2005, pp.43.

[15] Yao, S. "Economic Development and Poverty reduction in China over 20 Years of Reforms". Economic Development and Cultural Change, vol.48, no.3, pp.447-474, 2000.

[16] Wu, Y. Gender Gap in Educational Attainment in Urban and Rural China. Chinese Journal of Sociology, vol.32, no.4, pp.112-137, 2012.

[17] Li, Y. Institutional Change and Educational Inequality: Mechanisms in Educational Stratification in Urban China (1966-2003). Social Sciences in China, no.4, pp.97-109, 2006.

[18] Liu, A., Tong, X. The Present Situation of Gender Attitudes and the Factors Influencing Them: Based on the Third Survey of Women's Social Status in China. Social Sciences in China, no.2, pp.116-129, 2014

[19] Zhang, Y., Kao, G., Hannum, E. Do mothers in rural China practice gender equality in educational aspirations for their children? Comparative Education Review, vol.51, no.2, pp.131-157, 2007.

[20] Li, D., Tsang, M. Household Decisions and Gender Inequality in Education in Rural China. China: An International Journal, vol.1, no.2, pp.224-248, 2003.

[21] Hannum, E., Kong, P., Zhang, Y. Family sources of education gender inequality in rural china: A critical assessment. International Journal of Educational Development, vol.29, no.5, pp.474486, 2009

[22] Lee, M. The One-Child Policy and Gender Equality in Education in China: Evidence from household Data. Journal of Family and Economic Issues, vol.33, pp.41-52, 2012. 